\title{
Evaluation of outcome after primary median and/or ulnar nerve(s) repair at wrist: clinical, functional, electrophysiologic, and ultrasound study
}

Nahla Ahmed Hassan ${ }^{*}$, Noha Abdelhalim Elsawy, Hesham Hussien Kotb, Mowaffak Mostafa Abd El-Hamid, Wafaa Samir El Emairy and Hassan Mahmoud Kholosy

\begin{abstract}
Background: A major problem in surgery of peripheral nerve injuries of the upper extremities is the unpredictable final outcome. More insight and understanding of the proper methods of outcome assessment and the prognostic factors is necessary to improve functional outcome after repair of peripheral nerves. The objective of this study is to assess the outcome and identify possible prognostic factors for functional recovery of median and/or ulnar nerves repairs at wrist. Forty patients with median, ulnar or combined median-ulnar nerve injuries were included. Smoking, age, sex, repaired nerve, associated artery and/ or tendon repairs, joint stiffness and scar tissue were analyzed as prognostic factors for functional outcome after repair. Outcome parameters were medical research counsel (MRC) scoring for sensory and motor recovery, grip and pinch strength, disability of arm, shoulder and hand (DASH) questionnaire, electrophysiology and ultrasonographic evaluation.
\end{abstract}

Results: The mean age of the studied patients was $29.1 \pm 8.3$ and it was statistically correlated with grip strength ( $p$ $=0.045)$, DASH score $(p=0.046)$ and hyperesthesia score $(p=0.040)$. EMG results showed signs of regeneration in all patients in the form of small nascent MUAPs and polyphasic MUAPs. CMAP amplitudes of median and ulnar nerves positively correlated with the MRC scale for muscle strength ( $p=0.001)$

There were statistically significant negative correlations between DASH score and MRC score for sensory evaluation $(p=0.016)$, grip $(p=0.001)$, and pinch strength $(p=0.001)$. There were statistically significant positive correlations between patient's opinion of recovery and MRC score for sensory evaluation ( $p=0.029)$, grip $(p=0.001)$, and pinch strength $(p=0.001)$. The MRC score for muscle strength has statistical significant positive correlations with the MRC score for sensory evaluation, grip $(p=0.003)$, and pinch strength $(p=0.040)$

Conclusions: It was concluded that; MRC scale for muscle power, MRC scale for sensory evaluation, functional scores, grip and pinch strength are valuable tools for evaluation of functional outcome. Age, smoking, associated tendon repair, damaged nerve, compliance to rehabilitation protocol, return to work, clinically visible wound adhesions, residual hand joint stiffness, and scar tissue detected by ultrasound were found to be prognostic factors for outcome after nerve repair.

Keywords: Median, Ulnar, Functional outcome, Electrophysiology, Ultrasound

*Correspondence: nahlahassan1015@gmail.com

Department of Physical Medicine, Rheumatology and Rehabilitation,

Faculty of Medicine, Alexandria University, Alexandria, Egypt 


\section{Background}

Peripheral nerve lesions caused by direct trauma to the soft tissues or secondary to various types of fractures are not uncommon and result in considerable disability. Out of all patients admitted to level I trauma centers, it is estimated that 2 to $3 \%$ have peripheral nerve injuries [1]

The resulting impairment in hand function after nerve repair represents a major problem in activities of daily living (ADL) for the individual patient [2]. Although different treatments have been suggested, the vast majority of injuries are treated by surgical techniques using either direct nerve suture or nerve grafts [3]

Factors which influence the outcome are very important. It is difficult to ascertain the success of nerve repair. Regeneration time is unknown as comparable long-term results are uncertain. Therefore, the success of reconstructive surgery cannot be measured by sensory and motor recovery alone $[1,4]$.

Follow-up of patients with peripheral nerve lesions is normally done by clinical and electrodiagnostic tests. Often a trial of conservative treatment is instituted if a reconstructed nerve does not show adequate recovery on follow-up examinations [5]. Nevertheless, surgical revision would be an option if discontinuity due to loosened sutures, encasement of the nerve by scar tissue, or development of neuromas is diagnosed. The decision of whether a second-look operation should be performed is difficult in these cases, and any diagnostic modality that yields additional information about the state of the nerve may be helpful [6].

Sonography has proved to be efficient in the initial diagnosis of different types of nerve lesions such as nerve entrapment, nerve tumors, and traumatic nerve lesions. Therefore, it could be a suitable tool for the diagnostic follow-up of nerve reconstruction as well $[6,7]$.

Despite early nerve repair surgery and substantial improvements in surgical techniques, many of these patients stay symptomatic and normal function is seldom restored [2]. The aim of this work to evaluate the outcome of surgery after primary median and/or ulnar nerve (s) repair and identification of the possible factors affecting the outcome.

\section{Methods}

The study included 40 patients who underwent primary nerve reconstruction after complete injury. Eighteen patients for median nerve transection, 19 patients for ulnar nerve transection and 3 patients for both median and ulnar nerve injuries at wrist and distal forearm levels (at maximal distance of $5 \mathrm{~cm}$ proximal to wrist crease).

Patients were selected from those referred from the plastic surgery clinic to the outpatient clinic of Physical
Medicine, Rheumatology and Rehabilitation Department, Alexandria University Hospitals.

All patients underwent epineural suture technique for nerve repair. Patients were provided with a forearm dorsal splint postoperatively and splints were kept inplace for at least 6 weeks.

All patients had been seen after 2 weeks from the primary repair after suture removal where demographic, clinical and operative data were collected. Patients were enrolled for the rehabilitation program and evaluation of outcome was conducted for all patients at a mean time of 8 months since surgery (range 7-9 months) to perform clinical, functional, sonographic and electrophysiologic evaluation. Exclusion criteria were the presence of any kind of peripheral neuropathies and systemic diseases causing neuronal dysfunction such as diabetes mellitus.

Demographic data recorded for each patient including name, sex, age, smoking, occupation, and handedness. Surgical data including; associated arterial and tendon repairs as well as data related to post-operative care including wound infection, wound adhesions, drugs, and adherence to rehabilitation protocol were all recorded.

\section{Clinical evaluation of outcome}

a) Muscle power strength testing of abductor pollicis brevis (APB) and abductor digiti minimi (ADM) muscles for median and ulnar nerve injuries respectively graded by Medical Research Council (MRC) scale (grades M0-M5) [8].

b) Sensory testing was assessed according to the Medical Research Council (MRC) scale (SO-S4) at dig II and $\operatorname{dig} \mathrm{V}$ for median and ulnar nerves respectively [8].

c) Grip and pinch strength measured using a muscle hand- held dynamometer. This was bilaterally performed. Unaffected side measures were taken as control and the values were calculated as percentage from normal side [9].

\section{Functional evaluation of outcome}

A) The Arabic version of disability of arm, shoulder, and hand (DASH- Arabic) questionnaire was used [10]. The main part of the DASH is a 30-item disability/ symptom scale concerning the patient's health status during the preceding week. It included items which ask about the degree of difficulty in performing different physical activities because of the arm, shoulder, or hand problem (21 items), the severity of each of the symptoms of pain, activity-related pain, tingling, weakness, and stiffness (5 items), as well as 
the problem's impact on social activities, work, sleep, and self-image ( 4 items). Each item has five response options. The scores for all items are then used to calculate a scale score ranging from 0 (no disability) to 100 (most severe disability).

B) Assessment of patient's opinion of recovery on a 0-10 numeric rating scale [4].

C) Hyperesthesia is assessed using a four-point selfreport scale (0-3) $0=$ hinders function, $1=$ disturbing, $2=$ moderate, and $3=$ none/minor [4].

\section{Sonographic evaluation}

Sonographic evaluation was done using a GE Logic P7 machine using 6-12 $\mathrm{MHz}$ high frequency transducer. The probe was applied at the site of repair (scar area) Evaluation was done to assess; continuity of the repaired nerve, cross sectional area (CSA) in $\mathrm{mm}$ and detection of unfavorable local conditions that may be related to poor outcome such as neuromas, septic focus around the nerve, and scar tissue surrounding causing possible nerve compression.

\section{Electrophysiological evaluation 8 months postoperative:} $[11,12]$

a) Sensory conduction studies of the median and/ or ulnar nerves in the affected hand. Median nerve wrist-digit II antidromic sensory conduction study and/ or ulnar nerve wrist-digit $\mathrm{V}$ antidromic sensory conduction study.

b) Motor conduction studies of the median nerve recorded from APB muscle and/or ulnar nerves recorded from ADM muscle were done bilaterally. And percent of regeneration was calculated from the healthy side measurements.

c) Electromyography of the APB and/ or ADM muscles. The presence of abnormal spontaneous activity (fibrillations and positive sharp waves), motor unit action potentials (MUAPs) during voluntary muscle contraction and recruitment pattern were recorded.

\section{Statistics}

Data were analyzed using IBM SPSS software package version 20.0. Qualitative data were described using number and percent. Description of the quantitative data was done using the mean \pm SD in normally distributed data, whereas using the median (the minimum and the maximum) in abnormally distributed one.

Student's $t$ test was used for normally distributed quantitative variables, to compare between two studied groups, whereas Mann-Whitney test was used for abnormally distributed quantitative variables. Correlations between two quantitative variables were assessed using Spearman coefficient. Correlations and comparative studies were found to be significant at a $p$ level $<0.05$.

\section{Results}

This study included 18 patients with median nerve repair, 19 patients with ulnar nerve repair and 3 patients for with both median and ulnar nerve repairs. The demographic and clinical characteristics of the study patients are shown in Table 1.

Clinical evaluation of surgical outcome including the following:

1- MRC score for muscle strength assessment is shown in Fig. 1.

Good motor recovery (M3 or better) was shown in $68.5 \%$ of all patients; however, none of the patients had reached full motor recovery (M5).

2- Sensory testing according to the MRC scale (S0-S4) is shown in Fig. 2.

Most of the patients (85\%) by the time of assessment had regained some sensation but no one has reached S3+, S4 (2-point discrimination recovery), and 70\% (28 patients) of them had sensory recovery below S3. Among patients who had combined median and ulnar nerve repair (3 patients); the sensation in digit II and digit $V$ were grade 1, 2, and 3 for each.

3- Grip and pinch strength: Grip and pinch strength results of the studied patients were $36 \%$ and $29 \%$, respectively. For ulnar nerve repair patients; the median values for grip and pinch percentage were 39.4 and 47.05 , respectively. While for median nerve repair patients; the median values of the grip and pinch percentage were 24.8 and 22.2, respectively. For

Table 1 Demographics and clinical data

\begin{tabular}{ll}
\hline $\begin{array}{l}\text { Demographics: } \\
\boldsymbol{n}=\mathbf{4 0}\end{array}$ & \\
\hline Age (mean \pm SD) years & $29.1 \pm 8.3$ \\
Sex (male/female) & $35 / 5$ \\
Smoking & 19 \\
Injured nerve (median/ulnar/both) & $18 / 19 / 3$ \\
Tendon injury & 33 \\
Arterial injury & 12 \\
Post-operative wound infection & 2 \\
Clinically visible wound adhesions & 25 \\
Presence of pain by tapping on scar & 28 \\
Compliance to rehabilitation protocol & 35 \\
Residual hand joint stiffness & 7
\end{tabular}


combined median and ulnar nerve repaired patients; the median values for grip and pinch were 0 and 5, respectively.

\section{Functional evaluation of surgical outcome}

- The median value of DASH among all study patients was 28 (12-85). For median nerve was 38.5/100, for ulnar nerve was 36/100 and for patients with both nerve repair was 58/100.

- The median value of patient's opinion of recovery was 5 (1-9) and the distribution of patient's scores is showed in Fig. 3. The median value for patients with median nerve was 5 , for ulnar nerve was 6 , and for both nerve repair was 2 .

- The median value of hyperesthesia score was 3 (0-3) and the distribution of patient's scores is showed in Fig. 4 . The median value for hyperesthesia for median

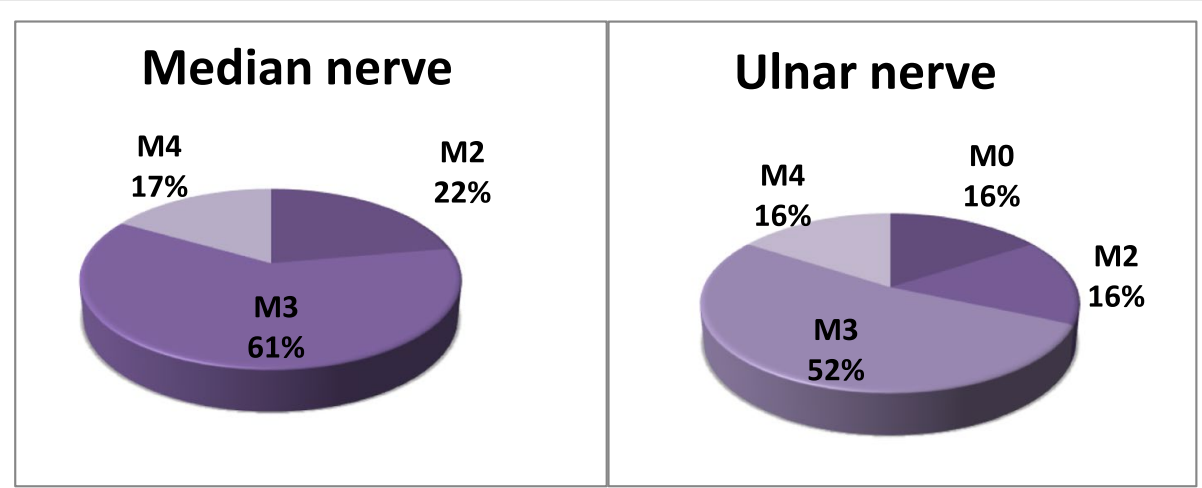

Fig. 1 Distribution of muscle grading of the median and ulnar nerve repaired patients according to MRC scale

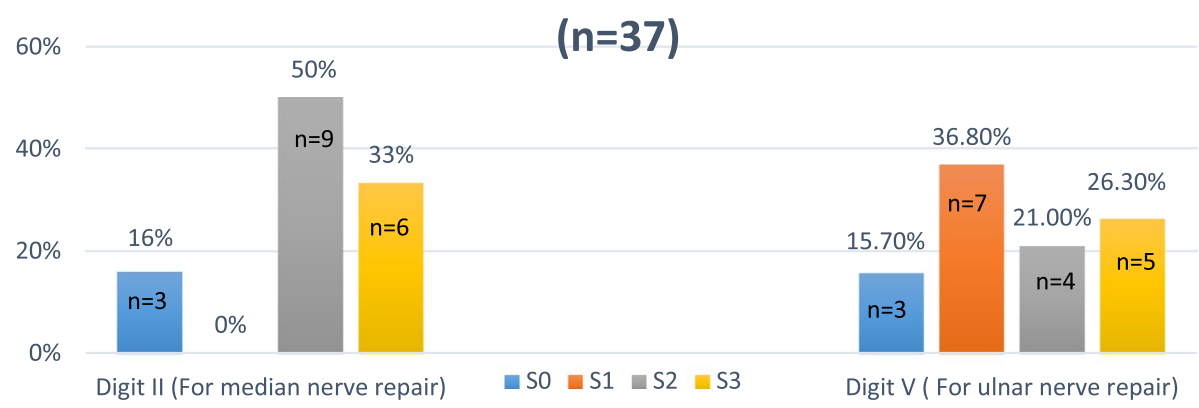

Fig. 2 Distribution of sensory grading of the median and ulnar nerve according to MRC scale

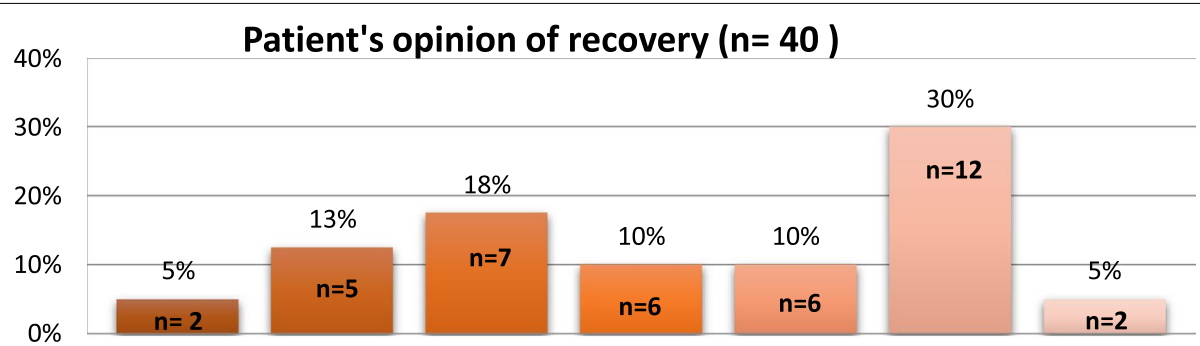

$\square 1 \square 2 \square 3 \square 5 \square 7 \square 8 \square 9$

Fig. 3 Distribution of study patients according to their self-rated opinion of recovery 


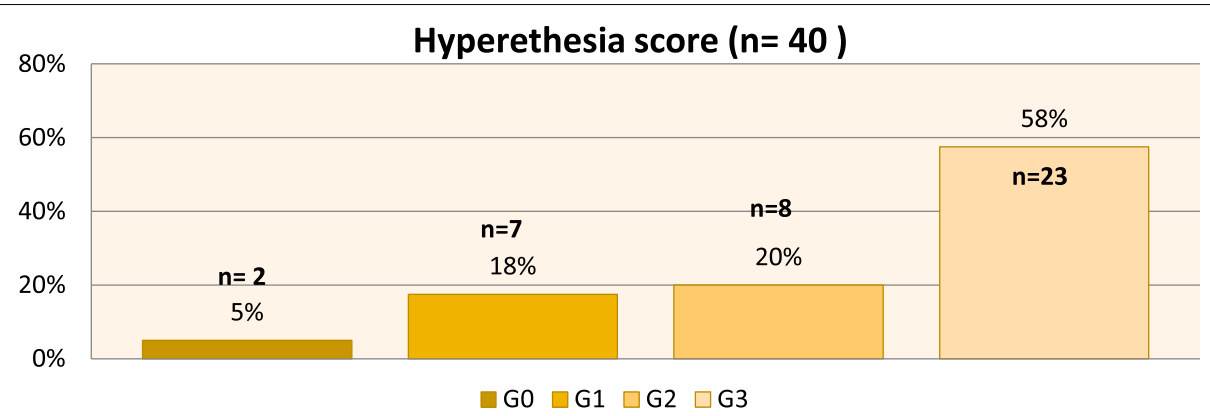

Fig. 4 Distribution of study patients according to hyperesthesia score

nerve was 2.5, for ulnar nerve was 3 and for patients with both nerve repair was 3 (Figs. 5 and 6).

\section{Sonographic evaluation of repaired nerve at the wound area}

All study subjects showed sonographic continuity of the repaired nerve/s. Hypoechoic nerve substance was present in 19 (72.5\%) patients, while 11(27.5\%) showed echogenic nerve substance. Twenty-two (55\%) subjects had no sonographically visible scar tissue, while 18 (45\%) subjects showed scar tissue formation. None of the 40 studied subjects had scar tissue compressing the nerve/s. None of the studied subjects had shown local sepsis or neuroma formation. The median values for the CSA $\left(\mathrm{mm}^{2}\right)$ were 12.9 and 4.2 for median and ulnar nerve respectively and there were no statistically significant differences compared to the healthy side measurements;
$9.95 \mathrm{~mm}^{2}$ for median nerve and $4.15 \mathrm{~mm}^{2}$ for ulnar nerve.

\section{Electrophysiological study}

Among patients with median nerve repair; only one patient had sensory response with a peak latency: 3.6 ms, SNAP amplitude: $5.4 \mu \mathrm{V}$ and NCV: $52.2 \mathrm{~m} / \mathrm{s}$. Among patients with ulnar nerve repair; only 3 patients had sensory response with a peak latency of 3.0, 3.9, and 3.5 ms, SNAP amplitude of 3.4, 2.5, and $6.2 \mu \mathrm{V}$ and NCV of $54.2,50$, and $49 \mathrm{~m} / \mathrm{s}$ respectively. Patients with combined median and ulnar nerve repair showed un-obtainable sensory response for both median and ulnar nerves.

The motor conduction parameters of the study subjects are shown in Table 2.

EMG results showed signs of regeneration in all patients; small nascent MUs and polyphasic MUAPs. All patients showed incomplete interference pattern.

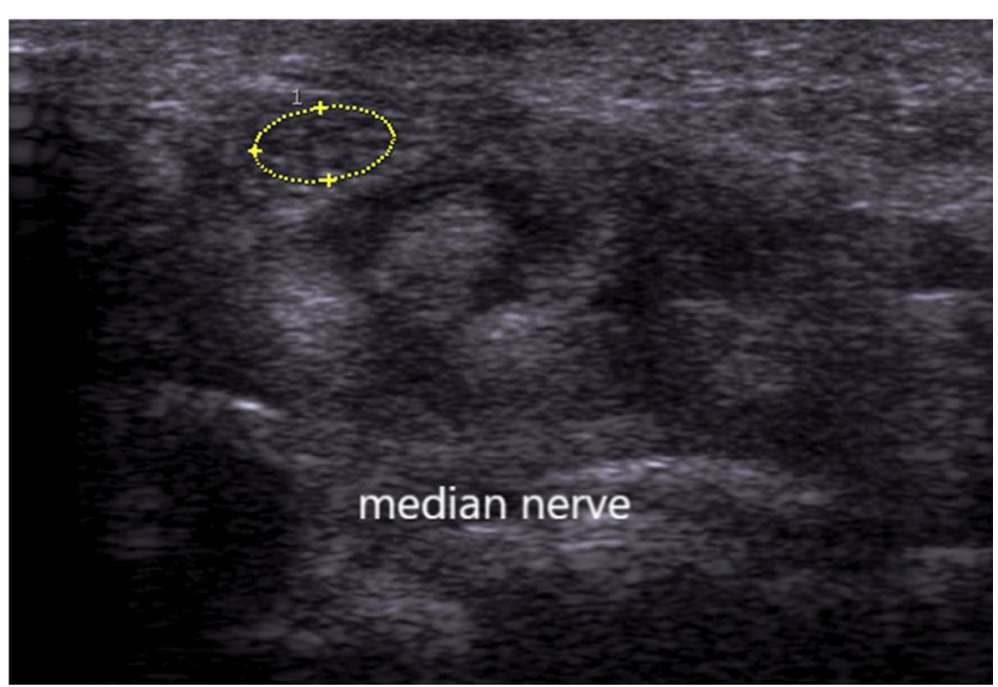

Fig. 5 Ultrasound image in transverse plain of one of the studied patients showing right median nerve of the injured hand at wrist region showing honeycomb appearance and echogenic pattern with a CSA of $9.5 \mathrm{~mm}^{2}$ 


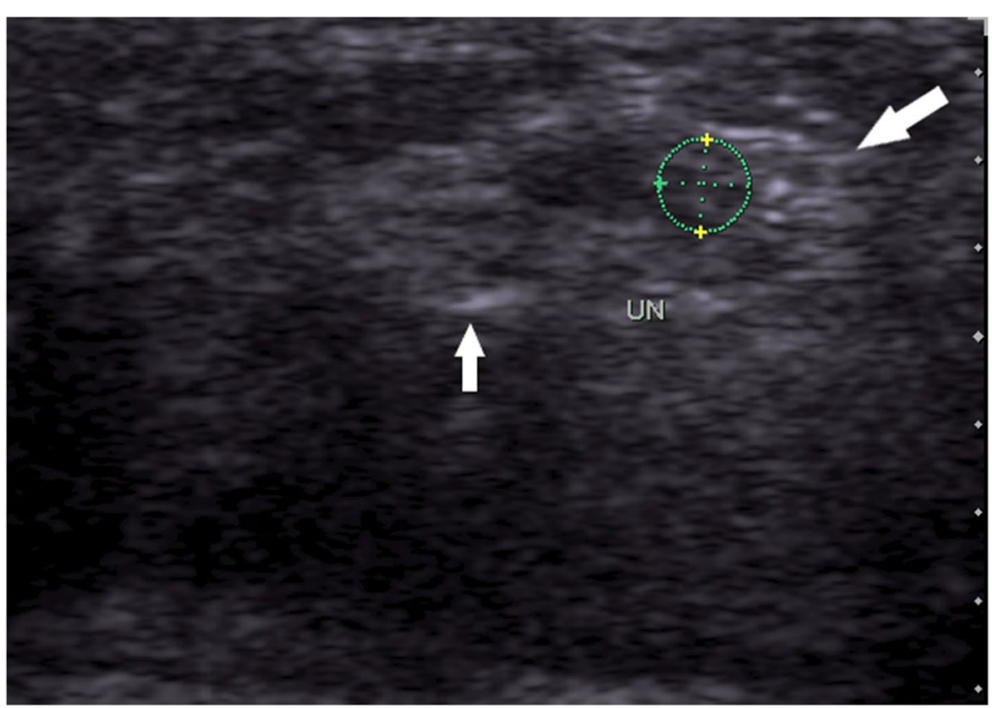

Fig. 6 Ultrasound image in transverse plain of one of the studied patients showing right ulnar nerve of the injured hand at wrist with a CSA of 4.2 $\mathrm{mm}^{2}$ and scattered scar tissue around (white arrows)

Table 2 Motor conduction study of the repaired median and ulnar nerves

\begin{tabular}{|c|c|c|c|c|}
\hline \multirow[b]{2}{*}{ Distal latency (ms) } & \multirow[t]{2}{*}{ Median nerve $(n=18)$} & \multirow{2}{*}{$\begin{array}{l}\text { Ulnar nerve } \\
(n=19)\end{array}$} & \multicolumn{2}{|c|}{ Combined median and ulnar $(n=3)$} \\
\hline & & & Median nerve & Ulnar nerve \\
\hline Min.-max. & $4.2-9.5$ & $3.9-7.3$ & $4.9-6.5$ & $3.6-4.5$ \\
\hline Median & 4.5 & 4.0 & 5.3 & 3.9 \\
\hline \multicolumn{5}{|l|}{ CMAP amplitude (mV) } \\
\hline Min.-max. & $0-3.6$ & $0-3.5$ & $3.5-4.1$ & $2.5-3.2$ \\
\hline Median & 1.0 & 1.0 & 3.6 & 2.7 \\
\hline $\begin{array}{l}\% \text { of regeneration } \\
\text { (min-max) (compared to the healthy } \\
\text { side) }\end{array}$ & $\begin{array}{l}13.65 \% \\
0-32.7\end{array}$ & $\begin{array}{l}11.1 \% \\
0-31.8\end{array}$ & $\begin{array}{l}23 \% \\
20-32\end{array}$ & $\begin{array}{l}27 \% \\
22.8-34\end{array}$ \\
\hline \multicolumn{5}{|l|}{$\mathrm{NCV}(\mathrm{m} / \mathrm{s})$} \\
\hline Min.-max. & $(46-55)$ & $(47-58)$ & $42-50$ & $47-58$ \\
\hline Median & 47.0 & 52.0 & 47.5 & 51.4 \\
\hline
\end{tabular}

ms millisecond, $m V$ millivolt, $\mathrm{m} / \mathrm{s}$ meter per second, $C M A P$ compound muscle action potential, $N C V$ nerve conduction velocity

\section{The relationship between the clinical and functional outcome assessment measures}

There were statistically significant negative correlations between DASH score and sensory assessment by MRC score $(p=0.016)$, grip $(p=0.001)$, and pinch strength $(p=$ $0.001)$. There were statistically significant positive correlations between patient's opinion of recovery and MRC score for sensory assessment $(p=0.029)$, grip $(p=0.001)$, and pinch strength $(p=0.001)$ (Table 3$)$.

\section{The relationship between the functional outcome measures used in the study}

DASH score has statistically significant negative correlations with both the hyperesthesia score $\left(r_{\mathrm{s}}=-530\right)$ $(p=0.001)$ and patient's opinion of recovery $\left(r_{\mathrm{s}}=-\right.$ 859) $(P=0.001)$. There were statistically significant positive relations between the patient's self-assessment score and hyperesthesia score $\left(r_{\mathrm{s}}=567\right)(P=0.001)$. 
Table 3 Correlation between functional outcome measures and SNAP amplitude, CMAP amplitude, MRC score, sensory assessment by MRC score, grip, and pinch strength

\begin{tabular}{|c|c|c|c|c|}
\hline \multicolumn{2}{|l|}{$\begin{array}{l}\text { Clinical measure } \\
\text { Functional measure }\end{array}$} & \multirow{2}{*}{$\begin{array}{l}\text { DASH score } \\
-0.080\end{array}$} & \multirow{2}{*}{$\begin{array}{l}\text { Hyperesthesia score } \\
-0.159\end{array}$} & \multirow{2}{*}{$\begin{array}{l}\text { Patient's } \\
\text { opinion o } \\
\text { recovery }\end{array}$} \\
\hline SNAP amplitude ( $\mu \mathrm{s})$ & $r_{\mathrm{s}}$ & & & \\
\hline & $p$ & 0.643 & 0.346 & 0.641 \\
\hline \multirow[t]{2}{*}{$\%$ of regeneration } & $r_{\mathrm{s}}$ & 0.106 & -0.206 & -0.177 \\
\hline & $p$ & 0.675 & 0.222 & 0.482 \\
\hline \multirow{2}{*}{$\begin{array}{l}\text { MRC score for muscle power } \\
(0-5)\end{array}$} & $r_{\mathrm{s}}$ & -0.425 & 0.116 & 0.423 \\
\hline & $p$ & 0.089 & 0.636 & 0.071 \\
\hline \multirow[t]{2}{*}{ Sensory assessment by MRC score (S0-S4) } & $r_{\mathrm{s}}$ & -0.543 & 0.322 & 0.502 \\
\hline & $p$ & $0.016^{*}$ & 0.179 & $0.029 *$ \\
\hline \multirow[t]{2}{*}{ Grip strength } & $r_{\mathrm{s}}$ & -0.743 & 0.250 & 0.713 \\
\hline & $p$ & $0.001 *$ & 0.136 & $0.001^{*}$ \\
\hline \multirow[t]{2}{*}{ Pinch strength } & $r_{\mathrm{s}}$ & -0.520 & 0.092 & 0.555 \\
\hline & $p$ & $0.001 *$ & 0.586 & $0.001 *$ \\
\hline
\end{tabular}

$r_{s}$ Spearman coefficient, MRC Medical Research Council, $\mu V$ microvolt, SNAP sensory nerve action potential

*Statistically significant at $p \leq 0.05$

\section{The relationship between nerve CSA and the clinical outcome measures}

There were no statistically significant correlations between the nerve CSA measured by ultrasound and each of the CMAP amplitude, the MRC scale for muscle power, MRC score for sensory assessment, grip and pinch strength.

\section{Comparison between the study subjects as regards the possible factors affecting surgical outcome}

In order to identify the possible relation of these factors with surgical outcome; we studied each of them separately in relation with each outcome measure that had been applied in this study (Table 4).

The outcome scores in the current study were divided into subjective scores including DASH score, hyperesthesia score and patient's opinion of recovery on a 0-10 scale, and objective scores; grip strength, pinch strength, the MRC score of muscle power (0-5), modified MRC score for sensory testing (0-4), CMAP amplitude, \% of regeneration, SNAP amplitude and nerve CSA measured by ultrasound.

The study results showed that patients with ulnar nerve repair had statistically better pinch strength ( $p$ $=0.002)$. There were statistically significant negative correlations between the age and the grip strength ( $p$ $=0.045)$, patient's opinion of recovery $(p=0.025)$, and hyperesthesia score $(p=0.040)$ and a statistically significant positive correlation between the age and the DASH score $(p=0.046)$ (Table 4$)$.
In the present study, non-smokers had statistically significant better grip strength $(p=0.021)$, patient's opinion of recovery $(p=0.030)$, and DASH score ( $p$ $=0.026)$. Patients with associated flexor tendon injury showed statistically significant worse DASH score ( $p=$ $0.042)$ and opinion of recovery $(p=0.027)$ (Table 4$)$.

Moreover, patients with clinically visible wound adhesions showed statistically significant worse grip strength $(p=.0016)$, patient's opinion of recovery $(p=0.001)$, hyperesthesia score $(p=.003)$, and DASH score $(p=$ 0.001) (Table 4).

Patients with residual hand joint stiffness showed statistically significant worse grip strength $(p=0.044)$, pinch strength $(p=0.040)$, patient's opinion of recovery $(p=0.033)$, and DASH score $(\mathrm{p}=0.018)$ (Table 4$)$.

\section{Discussion}

The current study has been conducted on 40 patients that had undergone primary median and/ or ulnar nerve (s) reconstruction and was planned to evaluate the outcome of surgery after primary nerve repair as well as the possible prognostic factors that may affect the outcome of primary median and/ or ulnar nerve (s) repair at wrist.

The results of current study showed that, $68.5 \%$ of patients had good motor recovery (M3, M4) and because of the distal site of injury (shorter distance to NMJ), this is a quite expected result. However, none of the patients had reached full motor recovery (M5) and this may be because of the relatively short period of follow-up where motor recovery continues years after nerve repair [13]. Similar to the current results, high percentage of good 
Table 4 Comparison between study subjects as regard the possible prognostic factors

\begin{tabular}{|c|c|c|c|c|c|c|c|}
\hline $\begin{array}{l}\text { Outcome measure } \\
\text { Prognostic factor }\end{array}$ & & Grip & Pinch & $\begin{array}{l}\text { Sensory } \\
\text { assessment by } \\
\text { MRC }\end{array}$ & DASH score & $\begin{array}{l}\text { Hyperesth- } \\
\text { esia score }\end{array}$ & $\begin{array}{l}\text { Patient's } \\
\text { opinion of } \\
\text { recovery }\end{array}$ \\
\hline \multirow[t]{4}{*}{ Nerve (median) } & Median nerve & - & 22.2 & - & - & - & - \\
\hline & Ulnar nerve & - & 47.0 & - & - & - & - \\
\hline & $U$ & - & 71 & - & - & - & - \\
\hline & $p$ & - & $0.002^{*}$ & - & - & - & - \\
\hline \multirow[t]{2}{*}{ Age } & $r_{\mathrm{s}}$ & -0.295 & - & - & 0.335 & -0.325 & -0.367 \\
\hline & $p$ & $0.045^{*}$ & - & - & $0.046^{*}$ & $0.040^{*}$ & $0.025^{*}$ \\
\hline \multirow{4}{*}{$\begin{array}{l}\text { Smoking } \\
\text { (median) }\end{array}$} & Yes & 23.8 & - & 1 & 55 & - & 3 \\
\hline & No & 39.4 & - & 3 & 24 & - & 7 \\
\hline & $U$ & 122 & - & 17.5 & 110 & - & 94.5 \\
\hline & $p$ & $0.021^{*}$ & - & $0.030^{*}$ & $0.026^{*}$ & - & $0.030^{*}$ \\
\hline \multirow{4}{*}{$\begin{array}{l}\text { Compliance to rehabilitation } \\
\text { (median) }\end{array}$} & Yes & 37.5 & 42.1 & - & 26 & - & 7 \\
\hline & No & 26 & 22.2 & - & 61 & - & 5 \\
\hline & $U$ & 25.5 & 16.5 & - & 12 & - & 23.5 \\
\hline & $p$ & $0.015^{*}$ & $0.005^{*}$ & - & $0.009^{*}$ & - & $0.011^{*}$ \\
\hline \multirow{4}{*}{$\begin{array}{l}\text { Return to work } \\
\text { (median) }\end{array}$} & Yes & 35.5 & 37.5 & - & 17 & 3 & 8 \\
\hline & No & 29.5 & 30.9 & - & 55 & 2 & 4 \\
\hline & $U$ & 49 & 69.5 & - & 13.5 & 68.5 & 30 \\
\hline & $p$ & $0.004^{*}$ & $0.023^{*}$ & - & $0.001^{*}$ & $0.015^{*}$ & $0.001^{*}$ \\
\hline \multirow{4}{*}{$\begin{array}{l}\text { Associated tendon repair } \\
\text { (median) }\end{array}$} & Yes & - & - & - & 43 & - & 5 \\
\hline & No & - & - & - & 22 & - & 8 \\
\hline & $U$ & - & - & - & 60.5 & - & 73 \\
\hline & $p$ & - & - & - & $0.042^{*}$ & - & $0.027^{*}$ \\
\hline \multirow{4}{*}{$\begin{array}{l}\text { Wound adhesions } \\
\text { (median) }\end{array}$} & Yes & 23 & - & - & 55 & 2 & 3.5 \\
\hline & No & 44.4 & - & - & 22 & 3 & 8 \\
\hline & $U$ & 87 & - & - & 33.5 & 80 & 44 \\
\hline & $p$ & $0.016^{*}$ & - & - & $0.001^{*}$ & $0.003^{*}$ & $0.001^{*}$ \\
\hline \multirow{4}{*}{$\begin{array}{l}\text { Residual joint stiffness } \\
\text { (median) }\end{array}$} & Yes & 22.6 & 17 & - & 70 & - & 4 \\
\hline & No & 37.5 & 42 & - & 26 & - & 7 \\
\hline & $U$ & 48 & 45.5 & - & 26 & - & 41 \\
\hline & $P$ & $0.044^{*}$ & $0.040^{*}$ & - & $0.018^{*}$ & - & $0.033^{*}$ \\
\hline \multirow{4}{*}{$\begin{array}{l}\text { Scar tissue by ultrasound } \\
\text { (median) }\end{array}$} & Yes & 21 & 17.3 & - & 58 & - & 3 \\
\hline & No & 44 & 44 & - & 24 & - & 8 \\
\hline & $U$ & 65.5 & 91.5 & - & 74 & - & 87.5 \\
\hline & $P$ & $0.002^{*}$ & $0.019^{*}$ & - & $0.006^{*}$ & - & $0.005^{*}$ \\
\hline
\end{tabular}

*Factor significantly correlated with outcome measure

- Factor didn't correlate with/ or affect outcome measure result, U Mann-Whitney test, $r_{s}$ Spearman coefficient, MRC Medical Research Council

clinical motor recoveries were reported in the literature in the first year after median and ulnar nerve repairs [1, $13,14]$.

Regarding motor recovery, the current results showed a less satisfactory grip and pinch strength measurements (36\% and 29\%, respectively). On the contrary, Rosen and Lundborg et al. [4] reported better grip strength recoveries of $88 \%$ and $89.9 \%$, respectively after median and ulnar nerve repairs and this may be related to their larger sample sizes and longer period of follow up.
A statistically positive correlation was found between grip and pinch strength of the studied patients and the MRC scale for muscle power assessment. The formation of power grasp requires synchrony between the extrinsic and intrinsic muscles of the hand. Accordingly, intrinsic loss will affect grip strength by disrupting the mechanics of grasp and depriving the hand of the intrinsic muscle force contribution [9]. This was in accordance with many studies in literatures $[3,4,9]$ showing that patients with better clinical 
motor recovery had had less disability and better ADL performance.

Most of the current study patients (85\%) had regained some sensation by the time of assessment but no one has reached S3+, S4 (2-point discrimination recovery) and $70 \%$ (28 patients) of them had sensory recovery below S3. This may be because of the relatively short followup period as sensory functions gradually improve over time and need longer period to recover completely. Several studies $[1,15,16]$ reported that the quality of sensory recovery improved from S1 to S3 by increasing the follow-up time and still complete (S4) recovery was not seen after 3 years of repair. However, the significant improvement was seen in the first 2 years [17].

The current study showed that sensory recovery was correlated with disability level and ADL performance and this result goes in agreement with Kadir et al. [15] and Rosen et al. [4] who reported poor functional evaluation in patients with median and ulnar nerve repairs with poor sensory grading.

Many studies in literature $[2-4,16]$ go in agreement with current results that motor recovery was better than sensory recovery regarding the MRC grading. This may be related to the shorter distance that motor fibers had to travel from repair site to the target muscle compared to the longer distance traveled by sensory fibers to reach sensory receptors. In addition, preferential reinnervation of motor pathways by motor axons may contribute to improve functional outcome of motor regeneration compared to sensory after nerve section.

The ADL instrument used in the present study was DASH score. DASH Score results varied widely between the studied patients with a minimum score of $12 / 100$ and a maximum score of $85 / 100$. DASH score was correlated with grip and pinch strength measurements indicating that recovery of motor function of the hand after nerve repair positively affects patient's daily living activities [10].

The current results showed that hyperesthesia score was correlated with the rest of functional scores indicating that hyperesthesia can affect ADL performance in patients after nerve repair. This may be due to disturbing nature of hyperesthesia and its affection on hand manipulation and control. Hyperesthesia score was used by Rosen et al. [4] as one of the three domains (motor domain/sensory domain/pain and discomfort) in his assessment model for evaluation of outcome after nerve repair. However, they showed no significant relations between hypersensitivity and ADL performance. They believe that hypersensitivity is often a problem only in early phases of rehabilitation [4].

The present study used a $0-10$ scale to express the patient's opinion of recovery as one of the functional assessment tools. Fifty percent of the patients gave score of $7 / 10$ or more. Furthermore, it was correlated with $\mathrm{DASH}$, hyperesthesia scores as well as clinical motor recovery and these results are in accordance with results by Rosen et al. (2000) [4]. Patient's opinion of recovery reflects the interplay between the outcome of surgery and its impact on ADL, social life, and patient's emotions and anxiety. Therefore, improvements in many disease aspects has its positive influence on patient's opinion.

As regards electrophysiological assessment, $90 \%$ of the studied patients had absent SNAP. This can be related to decreased number of regenerated axons with smaller than normal diameters as well as temporal dispersion caused by differences in the conduction velocities of different-sized myelinated axons affect the amplitude of sensory potentials $[18,19]$.

Contrary to SNAP, CMAP was recorded in $72.5 \%$ of the patients and the median value for percentage of regeneration was estimated as $13.65 \%$ for median nerve and $11.1 \%$ for ulnar nerve as compared to the healthy side. Krarup et al. [20] had reported similar percentages for CMAP improvement in the first year after median and ulnar nerve repairs. Navarro et al. [21] reported improvements in CMAP in the first year up to $30 \%$ compared to the healthy side.

The discrepancy between CMAP and SNAP in the current study may be explained by the ability of each regenerating motor axon to reinnervate as many as four to five times the normal number of muscle fibers, thereby compensating for the reduced number of axons that succeed in reaching the denervated muscle [22]. In addition, regeneration distance for sensory fibers (the distance from the tip of digit 3/digit 5 till the repair site) is much longer that the distance for motor fibers (the distance from the motor point of the muscle till the repair site) [19].

In the present study, CMAP and SNAP amplitude were not statistically correlated with motor recovery, sensory recovery, and functional scores. Furthermore, using CMAP and SNAP amplitudes to compare between the study patients did not show statistical significant difference regarding any of the studied prognostic factors. In addition, EMG study of ADM and APB muscles had showed signs of reinnervation (nascent and polyphasic MUs) in all of patients despite having some patients with poor clinical and functional outcome measures. The lack of association between clinical and electrophysiological parameters can be explained by incomplete remyelination with sufficient number of reinnervated fibers to produce a satisfactory clinical and functional recovery [18].

Palma et al. [22] had studied the prognostic role of EDX on nerve regeneration processes of different types of nerve lesions. They found no significant correlations 
between SNAP, CMAP, and/or reinnervation MUAPs and clinical outcome parameters. Furthermore, Annete et al. [18] revealed that sensory electrophysiological parameters are inadequate predictors of clinical sensory recovery after nerve repair.

The current work showed no statistical correlation between the nerve CSA and motor recovery, sensory recovery, CMAP, and functional scores. This might be related to the fact that ultrasound cannot visualize subfascicular details of regeneration such as endoneurial or axonal regrowth or distinguish absent or nonfunctional axons from functional axons [23].

Younger patients in the present study had better grip strength and better functional scores. This may be because younger patients have a stronger regenerative capacity and better adaptation to the reorganization of the CNS that follows nerve repair [6]. Functional recovery was reported to be significantly poorer in older patients, who have weaker nerve regenerative and compensatory capacity, relatively poor nutritional status and local circulation as well as fewer receptors because of age-related changes of the central nervous system [24].

No significant relation was found between gender as a prognostic factor and the studied outcome measures. This result goes in agreement with many studies that showed no difference between males and females regarding outcome after nerve repair $[1,14,25]$. However, a previously published meta-analysis reported that female gender has better recovery of motor function after the repair of mixed nerve injuries compared with male gender. It was suggested that women may have better compliance with postoperative adjuvant treatments such as neurotropic drugs and functional exercises than men [26].

In the present study, despite not reaching a statistically significant level, motor recovery in median nerve injury was better than that after ulnar nerve injury. This may be because ulnar nerve innervates a small volume of muscle with a small muscle fiber size and accordingly loss of innervation and rapid degeneration and atrophy of muscle fibers. Moreover, the present study showed poor motor recovery and functional evaluation in those patients with combined nerve injuries which might be related to associated extensive soft-tissue damage [27-29].

Many studies reported the negative effects of smoking on nerve healing $[28,30,31]$. Current results showed that smokers had poor sensory recovery, grip strength, and functional assessment than nonsmokers. This is because microangiopathy due to smoking may prevent migration of progenitor cells, which are essential for the healing process. In addition, patients with associated flexor tendon injury showed poor functional results than those with isolated nerve repair. This could be explained by increasing fibrous tissue formation at the site of a nerve repair which may impair tissue vitality and the process of nerve healing [32-37].

Studied patients with clinically visible wound adhesions showed poor results regarding grip strength and functional score. Wound adhesions may prevent muscles and joints from moving freely lead to more stiffness. In addition, excessive tension across the nerve suture line will increase the degree of fibrosis and this will impair the nerve healing process [32].

Seven of the studied patients had limited ROM of the hand joints and they showed worse grip, pinch strength, and functional assessment results compared to those who had full hand joint ROM. This result goes in agreement with many studies which reported that restoring full range of motion of hand and wrist joints is mandatory for proper hand function after peripheral nerve repair $[27,33,34]$.

Most of patients (87.5\%) were compliant to post-operative rehabilitation. Results showed that post-operative rehabilitation is one of the factors affecting surgical outcome after nerve repair. Proper rehabilitation ensures restoration of joint motion, reduces muscle wasting, decrease the formation of adhesions and maximizes sensory reeducation [38]. In addition, patients that returned to work early had better grip, pinch strength and functional assessment results than those who did not return to their work. Early return to work improves muscle strengths, sensory reeducation, physical, and mental health as well as decreases stress, pain, and depression in those patients [39].

Studied patients that had scar tissue around the repaired nerve by ultrasound showed worse motor and functional assessment results suggesting that scar tissue detection around the nerve is a possible factor for poor surgical outcome. Scar tissue formation just outside the injured nerve causes adhesion of nerve fibers to neighboring tissues, decreases mobility and causes vasospasm and traction injuries in the nerve vessels. Furthermore, it decreases nutrition by diffusion, inhibits nerve repair, slows axoplasmic flow, and negatively effects nerve degeneration, resulting in ischemia and irreversible injury to the nerve [32].

\section{Limitations of the study}

- The number of patients with post-operative infection and/or associated vessel injury needs to be increased for reliable results about the effect of these factors on surgical outcome.

- Although some of the studied patients had increased nerve CSA by US, it seems that their number was 
not enough to show a statistical significant difference with the healthy side measurements. Larger study sample may be needed

- The number of patients with combined nerve repair was too small for comparison with each single nerve repair.

\section{Conclusions}

- MRC scales for motor and sensory evaluation, functional scores, grip, and pinch strength measurements have proven to be valuable tools for evaluation of functional outcome after peripheral nerve repair.

- Electrophysiological assessment after nerve repair is useful for tracing regeneration progress but cannot be used alone for functional outcome assessment.

- Younger age, smoking, associated flexor tendon injury, residual hand joint stiffness, post-operative rehabilitation, presence of scar tissue by ultrasound, and return to work were all significant factors that could predict functional outcome after nerve repair.

\begin{abstract}
Abbreviations
MRC: Medical research council; DASH: Disability of hand, arm and shoulder; EMG: Electromyography; CMAP: Compound muscle action potential; SNAP: Sensory nerve action potential; MUAPs: Motor unit action potentials; ADL: Activity of daily living; APB: Abductor policies brevis; ADM: Abductor digiti minimi; US: Ultrasound; CSA: Cross-sectional area; ROM: Range of motion.
\end{abstract}

\section{Acknowledgements}

Not applicable.

\section{Authors' contributions}

Conception and design of the study: NE, MA, and NH. Recruitment of patients: $\mathrm{HK}$ and $\mathrm{NH}$. Ultrasound for the patients: HK. Electrophysiology of the patients: WE. Data collection: NH. Analyzing and interpreting data: NH and WE. Manuscript preparation and revision: NE, MA, WE, and NH. The authors have read and approved the final manuscript
\end{abstract}

\section{Funding}

The present work was not funded.

\section{Availability of data and materials}

The data that support this study are available at Nahla Ahmed Hassan (the corresponding author) on reasonable request.

\section{Declarations}

\section{Ethics approval and consent to participate}

Approval of study conduction was obtained from the Ethical Committee at the Faculty of Medicine, Alexandria University, FAW 00018699/020720. All patients included in this study gave written informed consent to participate in this research.

\section{Consent for publication}

Not applicable.

\section{Competing interests}

The authors declare that they have no competing interests.

Received: 17 August 2021 Accepted: 27 October 2021

Published online: 09 December 2021

\section{References}

1. Thomas V, Martin L, Sabine O (2007) Long-term results after primary microsurgical repair of ulnar and median nerve injuries A comparison of common score systems. Clin Neurol Neurosurg 109:263-271

2. Aberg M, Ljungberg C, Edin $E_{1}$ Jenmalm P, Millqvist $\mathrm{H}$ et al (2007) Considerations in evaluating new treatment alternatives following peripheral nerve injuries: a prospective clinical study of methods used to investigate sensory, motor and functional recovery. J Plast Aesthetic Surg 60:103-113

3. Rosén B (1996) Recovery of sensory and motor function after nerve repair: a ratioale for evaluation. J Hand Ther 9:315-327

4. Rosén B, Lundborg G (2000) A model instrument for the documentation of outcome after nerve repair. J Hand Surg 25:535-543

5. Rosen B, Lundborg G (2003) A new model instrument for outcome after nerve repair. Hand Clin 19:463-470

6. Novak CB (2003) Evaluation of the nerve-injured patient. Clin Plast Surg 30:127-138

7. Siegfried P, Christoph H, Johann W, Hildegunde P, Gerd B (2003) Sonographic evaluation of primary peripheral nerve repair. J Ultrasound Med 22:1317-1322

8. Paternostro-Sluga T, Grim-Stieger M, Posch M, Schuhfried O et al (2008) Reliability and validity of the Medical Research Council (MRC) scale and a modified scale for testing muscle strength in patients with radial palsy. J Rehabil Med 40(8):665-617

9. Mathiowetz V, Weber K, Volland G, Kashman N (1984) Reliability and validity of grip and pinch strength evaluations. J Hand Surg 9:222-226

10. Alotaibi NM, Aljadi SH, Alrowayeh HN (2016) Reliability, validity and responsiveness of the Arabic version of the Disability of Arm, Shoulder and Hand (DASH-Arabic). Disabil Rehabil 38(25):2469-2478

11. Preston DC, Shapiro BE (2007) Basic nerve conduction studies. In: Preston DC, Shapiro BE (eds) Electromyography and neuromuscular disorders: basic electromyography. Heinemann, Boston, pp 201-225

12. Preston DC, Shapiro BE (2007) Basic nerve conduction studies. In: Preston DC, Shapiro BE (eds) Electromyography and neuromuscular disorders: basic electromyography. Heinemann, Boston, pp 250-265

13. Chemnitz A, Björkman A, Dahlin LB, Rosén B (2013) Functional outcome thirty years after median and ulnar nerve repair in childhood and adolescence. J Bone Jt Surg Am 95:329-337

14. Kadir E, Yurdaer D, Saim Y, Arslan B (2005) The effect of injury level, associated injuries, the type of nerve repair, and age on the prognosis of patients with median and ulnar nerve injuries. Acta Orthop Traumatol Turc 39(4):322-327

15. Fakin RM, Calcagni M, Klein HJ, Giovanoli P (2015) Longterm clinical outcome after epineural coaptation of digital nerves. J Hand Surg Eur 6:114-122

16. He B, Zhu Z, Zhu Q, Zhou X, Zheng C, Pengliang L et al (2014) Factors predicting sensory and motor recovery after the repair of upper limb peripheral nerve injuries. Neural Regen Res 9(6):661-672

17. Ruijs AC, Jaquet JB, Kalmijn S et al (2005) Median and ulnar nerve injuries: a meta-analysis of predictors of motor and sensory recovery after modern microsurgical nerve repair. Plast Reconstr Surg 116(2):484-494

18. Anette C, Gert A, Birgitta R, Lars B, Anders B et al (2012) Poor electroneurography but excellent hand function 31 years after nerve repair in childhood. NeuroReport 24:6-9

19. Van De Kar THJ, Jaquet JB, Meulstee J, Molenaar CBH et al (2002) Clinical value of electrodiagnostic testing following repair of peripheral nerve lesions: A Prospective Study. J Hand Surg 27:345-349

20. Navarro X, Udina E (2009) Methods and protocols in peripheral nerve regeneration experimental research: part III-electrophysiological evaluation. Int Rev Neurobiol. 87:105-126

21. Kline D, Hudson A (1995) Nerve action potential recordings. In: Kline D, Hudson A (eds) Nerve injuries. WB Saunders Company, Philadelphia, pp 102-115 
22. Ciaramitaro P, Mondelli M, Rota E, Battiston B, Sard A, Pontini I et al (2016) Electrophysiological predictors of clinical outcome in traumatic neuropathies: a multicenter prospective study. Neurol Res Int 23:1-6

23. Zeidenberg J, Burks SS, Jose J, Subhawong TK, Levi AD (2015) The utility of ultrasound in the assessment of traumatic peripheral nerve lesions: report of 4 cases. Neurosurg Focus 39(3):E3

24. Özaksar K, Günay H, Küçük L, Coşkunol E (2017) Long-term results of primary repair of combined cuts on the median and ulnar nerves in the forearm. Ulus Travma Acil Cerrahi Derg 23(5):410-414

25. Czarnecki P, Górecki M, Romanowski L (2020) Factors affecting the final outcomes after reconstruction of the median and ulnar nerve at the level of the forearm: Analysis of 41 patients. Injury. 20-1383(20):30191-30191

26. Ertem K, Denizhan Y, Yoloğlu S, Bora A (2005) The effect of injury level, asso- ciated injuries, the type of nerve repair, and age on the prognosis of pa- tients with median and ulnar nerve injuries. Acta Orthop Traumatol Turc 39(4):322-327

27. Yin $\mathrm{H}$, Yi C, Zhu Y, Tian $\mathrm{G}$ (2015) long term results of delayed repair of median nerve injury. Chin J Reparative Reconstr Surg 29:986-991

28. Czarnecki P, Górecki M, Romanowski L (2020) Factors affecting the final outcomes after reconstruction of the median and ulnar nerve at the level of the forearm: Analysis of 41 patients. Injury 3(20):191-197

29. Stonner MM, Mackinnon ES, Kaskutas V (2020) Predictors of functional outcome after peripheral nerve injury and compression. J Hand Ther 22:1-6

30. Lee JJ, Patel R, Biermann JS, Dougherty PJ (2013) The musculoskeletal effects of cigarette smoking. J Bone Joint Surg Am 95:850-859

31. Wong LS, Martins-Green M (2004) First hand cigarette smoke alters fibroblast migration and survival: implications for impaired healing. Wound Repair Regen 12:471-484

32. Wang ML, Rivlin M, Graham JG, Beredjiklian PK (2019) Peripheral nerve injury, scarring, and recovery. Connect Tissue Res. 60(1):3-9

33. Lokesh Chowdary R, Rangdal S, Nagendra S, Yaligod V, Rudrappa GH (2015) Study of long term functional outcome after repaired volar cut wrist. J Evol Med Dent 4(9):2278-4802

34. Dhanaraju S, Kannan N et al (2018) Surgical outcome of prognostic factors for final outcome of hand function following primary median nerve repair. Int Surg J. 5(11):3672-3675

35. Noaman HH (2007) Management and functional outcomes of combined injuries of flexor tendons, nerves, and vessels at the wrist. Microsurgery 27:536-543

36. Mohammad H, Alireza H, Shadi S, Farhad N, Roya B (2015) Median and ulnar nerve injuries; what causes different repair outcomes? Adv Biomed Res 4:215-216

37. Millesi $H$ (2006) Factors affecting the outcome of peripheral nerve surgery. Microsurgery 26:295-302

38. Watts AMI, Greenstock M, Cole RP (1998) Outcome following the rehabilitation of hand trauma patients. The importance of a subjective functional assessment. J Hand Surg Br 23:485-489

39. Bruyns CNP, Jaquet J-B, Schreuders TAR et al (2003) Predictors for return to work in patients with median and ulnar nerve injuries original communications. J Hand Surg AM 28:28-34

\section{Publisher's Note}

Springer Nature remains neutral with regard to jurisdictional claims in published maps and institutional affiliations.

\section{Submit your manuscript to a SpringerOpen ${ }^{\circ}$ journal and benefit from:}

- Convenient online submission

- Rigorous peer review

- Open access: articles freely available online

- High visibility within the field

- Retaining the copyright to your article

Submit your next manuscript at $\boldsymbol{\nabla}$ springeropen.com 